Check for updates

Cite this: RSC Adv., 2017, 7, 49759

Received 14th July 2017

Accepted 20th October 2017

DOI: $10.1039 / c 7 r a 07741 f$

rsc.li/rsc-advances

\section{Fluoride doped $\mathrm{SrTiO}_{3} / \mathrm{TiO}_{2}$ nanotube arrays with a double layer walled structure for enhanced photocatalytic properties and bioactivity $\dagger$}

\author{
Chaorui Xue, (DD *a Shengliang Hu, (D) ${ }^{\text {a }}$ Qing Chang, ${ }^{a}$ Ying $\mathrm{Li}^{\mathrm{a}}{ }^{\mathrm{Xi}} \mathrm{Liu}^{\mathrm{a}}$ \\ and Jinlong Yang ${ }^{\text {ab }}$
}

Anodized $\mathrm{TiO}_{2}$ nanotube arrays have important applications in the area of photocatalysis and biomedicine. In this study, with the aim of improving the photocatalytic and biomedical properties of $\mathrm{TiO}_{2}$ nanotube arrays, we prepared both single and double layer walled $\mathrm{TiO}_{2}$ nanotube arrays and subjected them to hydrothermal treatment in strontium acetate solution. It was found that fluoride doped $\mathrm{SrTiO}_{3} / \mathrm{TiO}_{2}$ nanotube arrays could be formed after hydrothermal treatment without the failure of the single and double layer walled structure. In the case of fluoride doped $\mathrm{SrTiO}_{3} / \mathrm{TiO}_{2}$ nanotube arrays with a double layer walled structure, doping of fluoride induced a visible light response, formation of $\mathrm{SrTiO}_{3}$ benefited the separation of photogenerated electron-hole pairs, and the double layer walled structure led to an enlarged surface area. Due to the synergetic effect of above three factors, the fluoride doped double layer walled $\mathrm{SrTiO}_{3} / \mathrm{TiO}_{2}$ nanotube arrays demonstrated the highest photocatalytic activity under ultraviolet, visible and simulated solar light irradiation. The degradation rates of methylene blue solution are $0.13 \mathrm{~h}^{-1}, 0.26 \mathrm{~h}^{-1}$ and $0.53 \mathrm{~h}^{-1}$ respectively. Moreover, ability to induce hydroxylapatite formation on the surface was also examined through an immersing test in simulated body fluid. The results indicated that $\mathrm{SrTiO}_{3}$, doped fluoride and a double layer walled structure could stimulate the hydroxylapatite formation by providing a larger number of hydroxyl ions, hydroxyl radicals and reactive initiation sites, thus the fluoride doped double layer walled $\mathrm{SrTiO}_{3} / \mathrm{TiO}_{2}$ nanotube arrays also exhibited the best ability to form hydroxylapatite on the surface.

\section{Introduction}

Since the breakthrough work of preparing $\mathrm{TiO}_{2}$ nanotube arrays through anodization of titanium foil in fluoride containing solution by Zwilling et al., the anodized $\mathrm{TiO}_{2}$ nanotube arrays have attracted immense attention for functional applications in areas of dye sensitized solar cells, gas sensors, photocatalysis, biomedicine, ion insertion batteries, electrochromics etc. ${ }^{1-5} \mathrm{~A}$ particular advantage of anodized $\mathrm{TiO}_{2}$ nanotube arrays is that the nanotubes are fabricated from titanium metal without an immobilization process, the tubes can thus be straightforwardly used as a back contacted oxide electrode and surface coating material. ${ }^{6,7}$ It has been reported that classic quantum size effects on the electronic properties of $\mathrm{TiO}_{2}$ nanotube arrays is more significant than that for nanoparticulated $\mathrm{TiO}_{2}$ film, and therefore the electron scattering is reduced for anodized $\mathrm{TiO}_{2}$ nanotube arrays. ${ }^{8}$ Moreover, specific surface area of $\mathrm{TiO}_{2}$

${ }^{a}$ School of Materials Science and Engineering, North University of China, Taiyuan 030051, P. R. China. E-mail: crxue87@126.com

${ }^{b}$ School of Materials Science and Engineering, Tsinghua University, Beijing 100084, P. R. China

$\dagger$ Electronic supplementary information (ESI) available. See DOI: $10.1039 / \mathrm{c} 7 \mathrm{ra} 07741 \mathrm{f}$ nanotube arrays is relatively high for the one-dimensional nanotubular structure. These characters are scientifically exciting for the applications of solar cells, photocatalysis and biomedicine. However, many properties (e.g. photoelectric conversion efficiency, thermal stability, hydroxylapatite formation ability) of $\mathrm{TiO}_{2}$ nanotube arrays are intricately influenced by a number of geometric and compositional parameters (such as length, diameter). ${ }^{9} \mathrm{TiO}_{2}$ nanotube arrays still suffer the intrinsic deficits of $\mathrm{TiO}_{2}$, that are the poor visible light utilization efficiency as well as the high recombination rate of photogenerated electron-hole pairs. ${ }^{10}$ Specific surface area of anodized $\mathrm{TiO}_{2}$ nanotube arrays remain considerably lower than that of $\mathrm{TiO}_{2}$ nanoparticles. ${ }^{11}$ In this context, the aforementioned applications of $\mathrm{TiO}_{2}$ nanotube arrays still have the potential to be enhanced via devoting more comprehensive and consistent research work. For example, following the alkali treatments in $\mathrm{NaOH}$ solution, enhanced formation of hydroxylapatite has been achieved. ${ }^{12}$ Wang et al. prepared bamboo type $\mathrm{TiO}_{2}$ nanotube arrays by anodization under alternating voltage condition, and achieved higher efficiency solar cells for higher specific surface area. ${ }^{13}$ Numerous efforts have also been made to address this issue through geometry optimizing, metal or nonmetal ion doping, noble metal loading and hetero-coupling. ${ }^{14-17}$ 
It is widely known that perovskite-type titanates, such as lead titanate $\left(\mathrm{PbTiO}_{3}\right)$, barium titanate $\left(\mathrm{BaTiO}_{3}\right)$, strotinum titanate $\left(\mathrm{SrTiO}_{3}\right)$ and lead-zirconium titanate $\left(\mathrm{PbZrTiO}_{3}\right)$, have shown great potential applications in nanoscale electronics, photocatalytic and biomedical industry due to their inherent physical and chemical properties such as piezoelectricity, ferroelectricity, photoelectricity and good biocompatibility. ${ }^{\mathbf{1 8 - 2 0}}$ Therefore, researchers have also focused many interests and attempts to convert $\mathrm{TiO}_{2}$ nanotube arrays to perovskite-type titanate nanotube arrays for enhanced applications. In term of perovskite-type titanates, strontium titanate $\left(\mathrm{SrTiO}_{3}\right)$ has attracted many attention because of its similar band gap of $3.2 \mathrm{eV}$ and more negative conductive band edge compared to $\mathrm{TiO}_{2}{ }^{21}$ Through the coupling of $\mathrm{SrTiO}_{3}$, the Fermi level of $\mathrm{TiO}_{2}$ can shift to more negative potential, and the separation of photogenerated electron and hole pairs can be improved for higher photocatalytic performance. For instance, by means of hydrothermal treatment, $\mathrm{TiO}_{2}$ nanotube arrays have been converted into hetero-junction $\mathrm{SrTiO}_{3} / \mathrm{TiO}_{2}$ nanotube arrays, and it was found that the photocatalytic activity of $\mathrm{SrTiO}_{3} / \mathrm{TiO}_{2}$ nanotube arrays increased and depended on the hydrothermal reaction time. ${ }^{22}$ Moreover, strontium is effective in reducing the incident of fractures in osteoporotic patients, and $\mathrm{SrTiO}_{3}$ has also been reported to hold excellent stability and biocompatibility. ${ }^{23}$ Zhang et al. prepared the hetero-junction $\mathrm{SrTiO}_{3} / \mathrm{TiO}_{2}$ nanotube arrays by hydrothermal treatment of $\mathrm{TiO}_{2}$ nanotube arrays and obtained improved bioactivity for the hydroxylapatite formation. ${ }^{24} \mathrm{Li}$ et al. further found that $\mathrm{SrTiO}_{3} / \mathrm{TiO}_{2}$ nanotube arrays can stimulate the secretion of cell filopodia, leading to enhanced cell proliferation. ${ }^{25}$ Considering above, coupling of $\mathrm{SrTiO}_{3}$ is benefit for obtaining improved photocatalytic and biomedical properties of anodized $\mathrm{TiO}_{2}$ nanotube arrays.

Recently, advanced double layer walled structure has been obtained under specific anodization conditions for $\mathrm{TiO}_{2}$ nanotube arrays. ${ }^{26,27}$ The double layer walled morphology occurs likely as a tube in tube structure. In this case, the porosity of tube wall could be induced, and a higher specific surface area and enhanced photocatalytic activities have been obtained. ${ }^{28}$ This suggests that double layer walled structure also provides a highly vivid picture for aim of enhancing many properties of $\mathrm{TiO}_{2}$ nanotube arrays. However, to the best of our knowledge, conversion of double layer walled $\mathrm{TiO}_{2}$ nanotube arrays into perovskite-type titanate nanotubes by hydrothermal treatment has not yet been conducted. The evolutions in morphology, composition, photocatalytic activity and bioactivity of nanotube arrays after hydrothermal treatment are not clear. This has inspired us with the means to conduct detailed research on the preparation, chemical composition and property of double layer walled hetero-junction $\mathrm{SrTiO}_{3} / \mathrm{TiO}_{2}$ nanotube arrays. Therefore, in the present work, we reported for the first time the production of double layer walled hetero-junction $\mathrm{SrTiO}_{3} / \mathrm{TiO}_{2}$ nanotube arrays via hydrothermal treatment of double layer walled $\mathrm{TiO}_{2}$ nanotube arrays in strontium acetate solution. The fluoride doped single and double layer walled $\mathrm{SrTiO}_{3} / \mathrm{TiO}_{2}$ nanotube arrays have been achieved and detailedly characterized. When used as photocatalytic and biomedical materials, it exhibited improved organic pollutant degradation and hydroxylapatite formation abilities. The detailed mechanism for the improvement was also investigated and discussed by comparing with other as prepared samples of single-layer walled $\mathrm{SrTiO}_{3} / \mathrm{TiO}_{2}$ nanotube array, single and double layer walled $\mathrm{TiO}_{2}$ nanotube arrays. Our results represented a promising vista of producing other advanced perovskite-type titanate nanotube arrays for a diversity of applications.

\section{Experimental}

\subsection{Materials and chemicals}

The titanium foil used in this work was purchased from Alfa Aesar (0.25 mm thickness; 99.5\% purity). Acetone, ethanol, sulfuric acid, hydrogen peroxide, nitric acid, ammonia fluoride, ethylene glycol and glycerol were all analytical purity and purchased from Sinopharm Chemical Reagent Co., Ltd. Methylene blue (MB), strontium acetate and sodium hydroxide of analytical purity were purchased from Aladdin Reagent. The simulated body fluid (SBF) was purchased from Beijing Leagene Biotech. Co., Ltd.

\subsection{Synthetic procedures}

Preparation of double and single layer walled $\mathrm{TiO}_{2}$ nanotube arrays. The titanium foil was firstly cut into sizes of $10 \times 20 \mathrm{~mm}$, then ultrasonic washed for about $5 \mathrm{~min}$ in acetone, ethanol, and purified water successively. A two electrodes system with anode electrode of titanium foil and cathode electrode of platinum foil was used for the anodization experiment. Firstly, the anodization was carried out in the electrolyte containing $57.7 \mathrm{~g}$ ethylene glycol, $1.8 \mathrm{~g}$ purified water and $0.3 \mathrm{~g}$ ammonia fluoride. Anodization voltage was $50 \mathrm{~V}$, time was $1 \mathrm{~h}$. After the first step, the obtained samples were washed with ethanol for several times, then ultrasonic treatment in purified water for about $3 \mathrm{~min}$ to remove the as-anodized oxide film, and titanium foils with mirror-like surface were obtained. Secondly, the titanium foil with mirror like surface was anodized again under $60 \mathrm{~V}$ for $1.5 \mathrm{~h}$ in the solution which consists of $57.9 \mathrm{~g}$ glycerol, $1.8 \mathrm{~g}$ purified water and $0.3 \mathrm{~g}$ ammonia fluoride. The second anodized samples were washed with ethanol for several times, dried under ambient condition. Finally, the double layer walled $\mathrm{TiO}_{2}$ nanotube arrays were obtained. The single layer walled $\mathrm{TiO}_{2}$ nanotube arrays were obtained by chemical etching of double layer walled $\mathrm{TiO}_{2}$ nanotube arrays. Firstly, the double layer walled $\mathrm{TiO}_{2}$ nanotube arrays were kept under $150{ }^{\circ} \mathrm{C}$ for $1 \mathrm{~h}$. Afterwards, the samples were dipped into piranha solution $\left(\mathrm{H}_{2} \mathrm{SO}_{4}: \mathrm{H}_{2} \mathrm{O}_{2}=3: 1\right.$, volume ratio) for $330 \mathrm{~s}$ at $70{ }^{\circ} \mathrm{C}$, then washed with purified water and dried under ambient air condition.

Preparation of hetero-junction $\mathrm{SrTiO}_{3} / \mathrm{TiO}_{2}$ nanotube arrays. The above as anodized $\mathrm{TiO}_{2}$ nanotube arrays were utilized for the preparation of $\mathrm{SrTiO}_{3} / \mathrm{TiO}_{2}$ nanotube arrays through hydrothermal treatment in sodium hydroxide solution $(\mathrm{pH}=$ 12) with $0.04 \mathrm{~mol} \mathrm{~L}^{-1}$ strontium acetate inside. The solution was filled into a Teflon lined stainless autoclave $(80 \%$ of total volume of $40 \mathrm{~mL}$ ) with $\mathrm{TiO}_{2}$ nanotube arrays at the bottom facing upside. Then the autoclave was sealed and heated at 
$200{ }^{\circ} \mathrm{C}$ for $2 \mathrm{~h}$. After hydrothermal treatment, the samples were washed with nitric acid $\left(0.1 \mathrm{~mol} \mathrm{~L}^{-1}\right)$ and purified water, and then dried under ambient air condition.

\subsection{Photocatalytic activity and bioactivity test}

Before photocatalytic activity and bioactivity test, the obtained samples were annealed at $450{ }^{\circ} \mathrm{C}$ in dry air for $3 \mathrm{~h}$ with rate of $5{ }^{\circ} \mathrm{C} \min ^{-1}$ during heating and cooling process. The as annealed samples were denoted as STNT for single layer walled $\mathrm{TiO}_{2}$ nanotube arrays, DTNT for double layer walled $\mathrm{TiO}_{2}$ nanotube arrays, SSTNT for single layer walled $\mathrm{SrTiO}_{3} / \mathrm{TiO}_{2}$ nanotube arrays, and DSTNT for double layer walled $\mathrm{SrTiO}_{3} /$ $\mathrm{TiO}_{2}$ nanotube arrays respectively. For the photocatalytic test, samples of $1 \mathrm{~cm}^{2}$ reaction area were put into a quartz cell containing $4 \mathrm{~mL} \mathrm{MB}$ solution with concentration of $1 \mathrm{mg} \mathrm{L}^{-1}$. A $500 \mathrm{~W}$ Xenon lamp was employed as light source. The light was passed through glass filters of QD254, UVCUT420 and AM1.5 for achieving ultraviolet, visible and simulated solar light irradiation. The light intensities of ultraviolet, visible and simulated solar light are $1.1,9.3,25.8 \mathrm{~mW} \mathrm{~cm}^{-2}$ respectively. The absorbance of MB solution was measured every $30 \mathrm{~min}$ for $3 \mathrm{~h}$ with a UV-vis spectrometer (UV-2550). The absorption maximum of spectra showed a peak at $664 \mathrm{~nm}$ whose density was measured for the calculation of degradation rate of MB solution. For the bioactivity test on the hydroxylapatite formation ability of samples, each sample was immersed in a Teflon vial containing $30 \mathrm{~mL}$ of SBF solution and was kept under static conditions at $36.5{ }^{\circ} \mathrm{C}$. The SBF solution was refreshed every two days. After immersion for total of 18 days, the samples were removed from the Teflon vial, rinsed with purified water and dried under ambient air condition.

\subsection{Characterization}

The crystal structure of samples were examined by X-ray diffractiometer (XRD, DX2700B) at a scan rate of $0.06^{\circ} \mathrm{s}^{-1}$. The surface and lateral morphologies of the samples were observed using a scanning electron microscope (SEM, JSM-7001F). Transmission electron microscopy (TEM, JEM-2100F) equipped with an energy dispersive X-ray spectrometer (EDX) operating at $200 \mathrm{KV}$ was employed to observe the microstructure and elemental compositions of the samples. X-ray photoelectron spectroscopy experiments were performed on the sample using a thermo scientific ESCALAB 250Xi XPS system using $\mathrm{Al}$ anode. The optical characterization of the films was conducted using a UV-vis spectrometer (UV-2550). The photocurrent spectra of the samples were studied on CHI660D electrochemical workstation in $0.1 \mathrm{~mol} \mathrm{~L}^{-1} \mathrm{Na}_{2} \mathrm{SO}_{4}$ solution using a three electrode configuration with the nanotube arrays as photoanodes (illumination area $=1 \mathrm{~cm}^{2}$ ), saturated $\mathrm{Ag} / \mathrm{AgCl}$ as the reference electrode, and platinum foil as the counter electrode. The applied potential is $0.3 \mathrm{~V}$ ( $v s$. $\mathrm{Ag} / \mathrm{AgCl})$. The light source was a $500 \mathrm{~W}$ Xenon lamp equipped with an AM1.5 filter. The dye loading measurements were carried out by immersing the samples in a $6 \mathrm{mM}$ solution of Ru-based dye (cis-bis(isothiocyanato)bis(2,2-bipyridyl-4,4-dicarboxylato)ruthenium(II)bis(tetrabutylammonium)) at $40{ }^{\circ} \mathrm{C}$ for $24 \mathrm{~h}$. After immersion, the samples were rinsed with ethanol and the soaked in an aqueous solution of $5 \mathrm{~mL} \mathrm{KOH}(10 \mathrm{mM})$ for $30 \mathrm{~min}$. The concentration of desorbed dye was measured by using UV-vis spectrometer (UV2550) at $\lambda=502 \mathrm{~nm}$. BET specific surface area measurements were carried out on a basis of $\mathrm{N}_{2}$ adsorption by using an ASAP2020C surface area and porosity analyser.

\section{Results and discussion}

Fig. 1 shows the surface and lateral SEM images of as-anodized $\mathrm{TiO}_{2}$ nanotube arrays with and without the hydrothermal treatment after annealing at $450{ }^{\circ} \mathrm{C}$ for 3 hours. Obviously, the samples demonstrated highly-ordered nanotubular structure both before and after hydrothermal treatment (Fig. 1a and c). With hydrothermal treatment, nanotubes showed average outer diameter of around $160 \mathrm{~nm}$, which is similar to that of nanotubes without hydrothermal treatment (Fig. 1b and d). This indicates that the integrated nanotube arrays have been preserved well during hydrothermal reactions. Generally, the asanodized $\mathrm{TiO}_{2}$ nanotube arrays are not stable during hydrothermal process, and can easily be converted to anatase $\mathrm{TiO}_{2}$ nanoparticles following the reactions below: ${ }^{29}$

$$
\begin{gathered}
\mathrm{TiO}_{x}+4 \mathrm{H}_{2} \mathrm{O}+(1-x / 2) \mathrm{O}_{2} \rightarrow \mathrm{Ti}(\mathrm{OH})_{6}{ }^{2-}+2 \mathrm{H}^{+}(1<x<2) \\
\mathrm{Ti}(\mathrm{OH})_{6}{ }^{2-}+2 \mathrm{H}^{+} \rightarrow \mathrm{TiO}_{2} \downarrow+\mathrm{H}_{2} \mathrm{O}
\end{gathered}
$$

Clearly, the growth of anatase $\mathrm{TiO}_{2}$ nanoparticles is strongly affected by the concentration of $\mathrm{H}^{+}$. Herein, since the $\mathrm{pH}$ value of solution is high $(\mathrm{pH}=12)$, the formation of anatase $\mathrm{TiO}_{2}$ from $\mathrm{Ti}(\mathrm{OH})_{6}{ }^{2-}$ is prevented, thus the tubular structure is retained. Despite this, it is observable that tube wall thickness increased after hydrothermal treatment (Fig. 1a and c). This could be caused by the incorporation of strontium ions into nanotube which might induce volume expansion of nanotube. Though the nanotube arrays appear smooth on the surface and lateral images (Fig. 1a-c), closer observation on the microstructure from nanotube bottom disclosed that the tube wall contained two layers of outer and inner layers inside (inset images in Fig. 1b and d). During anodization process, the relatively high anodization voltage can cause the decomposition

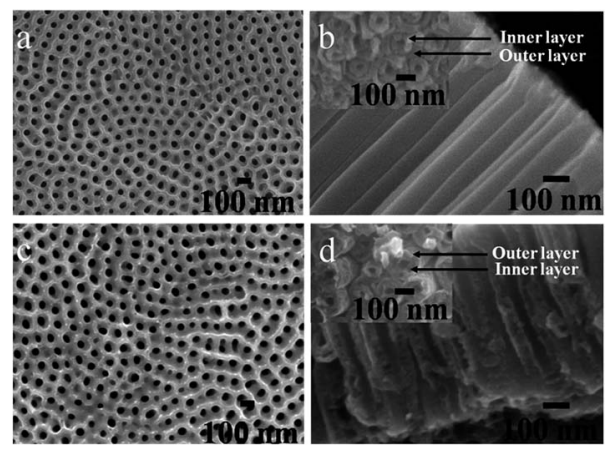

Fig. 1 SEM images of $(a, b)$ as-anodized $\mathrm{TiO}_{2}$ nanotube arrays (DTNT) and (c, d) $\mathrm{SrTiO}_{3} / \mathrm{TiO}_{2}$ nanotube arrays (DSTNT) with double layer walled structure. 
of glycerol, produce glyceric, glycolaldehyde and glycolic acid etc., which may react with $\mathrm{Ti}^{4+}$ at the oxide/electrolyte interface, and finally form the double layer walled structure. ${ }^{30,31}$ Notably, as shown in Fig. 1d, the double layer walled structure was also maintained well after hydrothermal treatment. Therefore, through anodization, well organized double layer walled $\mathrm{TiO}_{2}$ nanotube arrays have been obtained, the double layer walled nanotubular structure remained almost unchanged after hydrothermal treatment in strontium acetate containing solution with $\mathrm{pH}$ value of 12 .

The inner wall, which is formed due to the decomposition of glycerol, is intrinsic loose and porous for the uptake of carbon..$^{32}$ Thus, it has been chemically removed by using piranha solution in our experiment, and single layer walled $\mathrm{TiO}_{2}$ nanotube arrays were attained. As shown in inset images of Fig. 2b, $\mathrm{TiO}_{2}$ nanotubes clearly consist of only one layer in tube wall, accompanied by compactly integrated structure of nanotube array as that before piranha solution etching (Fig. 2a and b). On the basis of etching out of inner layer, hydrothermal treatment in strontium acetate solution was also applied to single layer walled $\mathrm{TiO}_{2}$ nanotube arrays. The same as double layer walled nanotube, no morphological failure was observed. The tube wall also became thicker probably due to the incorporation of strontium. As a consequence, single layer walled $\mathrm{TiO}_{2}$ nanotubes have been successfully obtained via chemical etching using piranha solution, its integrated nanotubular structure is also robust when subjected to hydrothermal treatment in $\mathrm{Sr}^{2+}$ containing solution.

Fig. 3 shows the TEM/EDX results of double and single layer walled $\mathrm{SrTiO}_{3} / \mathrm{TiO}_{2}$ nanotubes. Initially, the loose inner layer of tube wall, which can be observed clearly for double layer walled nanotube shown in Fig. 3a, disappeared for single layer walled nanotube shown in Fig. 3c. This is in accordance with the SEM results of Fig. 1 and 2, and further proved the successful etching out of inner layer using piranha solution. Furthermore, elemental composition measurement has also been performed perpendicular to a single nanotube, and the EDX profiles are shown respectively in Fig. $3 \mathrm{~b}$ and d. According to the EDX profiles, Ti, O, F and $\mathrm{Sr}$ exist for both double and single layer walled nanotubes, indicating the successful incorporation of strontium ions during hydrothermal process. Whereas, fluoride

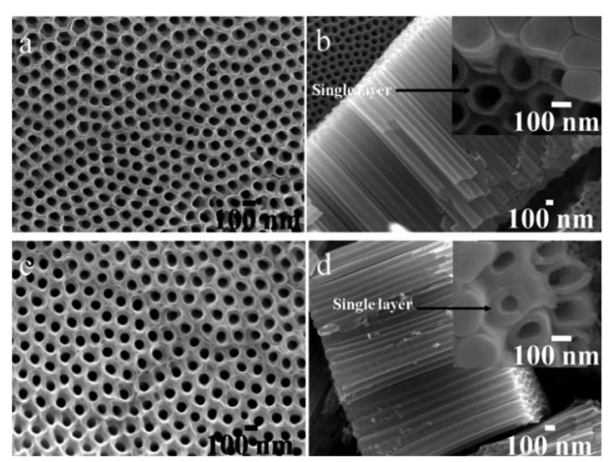

Fig. 2 SEM images of $(a, b)$ as-synthesized $\mathrm{TiO}_{2}$ nanotube arrays (STNT) and (c, d) $\mathrm{SrTiO}_{3} / \mathrm{TiO}_{2}$ nanotube arrays (SSTNT) with single layer walled structure.


Fig. 3 TEM images and EDX spectra of $(a, b)$ double and ( $c, d)$ single layer walled $\mathrm{SrTiO}_{3} / \mathrm{TiO}_{2}$ nanotube arrays. inner layer region.

ions should come from the anodizing process, where $\mathrm{TiF}_{4}$, $\mathrm{TiOF}_{2}$ and pentafluoro-aquo-titanate can be formed and cause the uptake of fluoride inside nanotubes. ${ }^{33,34}$ This can also be confirmed in XPS spectra of as anodized double layer walled $\mathrm{TiO}_{2}$ nanotube arrays shown in Fig. S1. $\dagger$ Fluoride peak can be observed clearly in the wide scanning spectrum. Moreover, in Fig. 3b, it can be observed that the Sr content in the outer layer region is higher than that in the inner layer region, explaining that strontium was mostly accumulated in the outer layer other than the inner layer of tube wall. TEM/EDX mapping of Fig. S2f $\uparrow$ further consolidates that strontium favours the outer layer of tube wall, wherein accumulation of $\mathrm{Sr}$ can be observed clearly inside. During hydrothermal treatment, dissolution of $\mathrm{TiO}_{2}$ and precipitation of $\mathrm{SrTiO}_{3}$ will occur according to the reactions below: ${ }^{35,36}$

$$
\begin{aligned}
& \mathrm{TiO}_{2}+2 \mathrm{OH}^{-}+2 \mathrm{H}_{2} \mathrm{O} \rightarrow\left[\mathrm{Ti}(\mathrm{OH})_{6}\right]^{2-} \\
& \mathrm{Sr}^{2+}+\left[\mathrm{Ti}(\mathrm{OH})_{6}\right]^{2-} \rightarrow \mathrm{SrTiO}_{3}+3 \mathrm{H}_{2} \mathrm{O}
\end{aligned}
$$

As previous mentioned, the inner layer of double layer walled nanotubes suffered higher carbon contamination for glycerol decomposition, and thus content of $\mathrm{TiO}_{2}$ in the inner layer should be lower than that in the outer layer. Hence, based on above chemical reactions, $\mathrm{SrTiO}_{3}$ formation in the outer layer might be more sufficient than that in the inner layer, that is, strontium prefer accumulating in the outer layer of tube wall rather than the inner layer.

XRD analysis was conducted to investigate the crystal structures of annealed $\mathrm{TiO}_{2}$ and $\mathrm{SrTiO}_{3} / \mathrm{TiO}_{2}$ nanotube arrays. After annealing at $450{ }^{\circ} \mathrm{C}$ for $3 \mathrm{~h}$, XRD patterns shown in Fig. $4 \mathrm{a}$ revealed that the crystal nature of both double and single layer walled $\mathrm{TiO}_{2}$ nanotube arrays crystallized into anatase phase with apparent anatase diffraction peaks. Differently, for the two samples which have been subjected to hydrothermal treatment in $\mathrm{Sr}^{2+}$ containing solution, additional diffraction peaks corresponding to perovskite $\mathrm{SrTiO}_{3}$ appeared $\left(2 \theta=32.5^{\circ}\right)$, confirming that part of $\mathrm{TiO}_{2}$ nanotube was converted into $\mathrm{SrTiO}_{3}$. This was also confirmed in Fig. S5, $\uparrow$ which demonstrates the XRD 

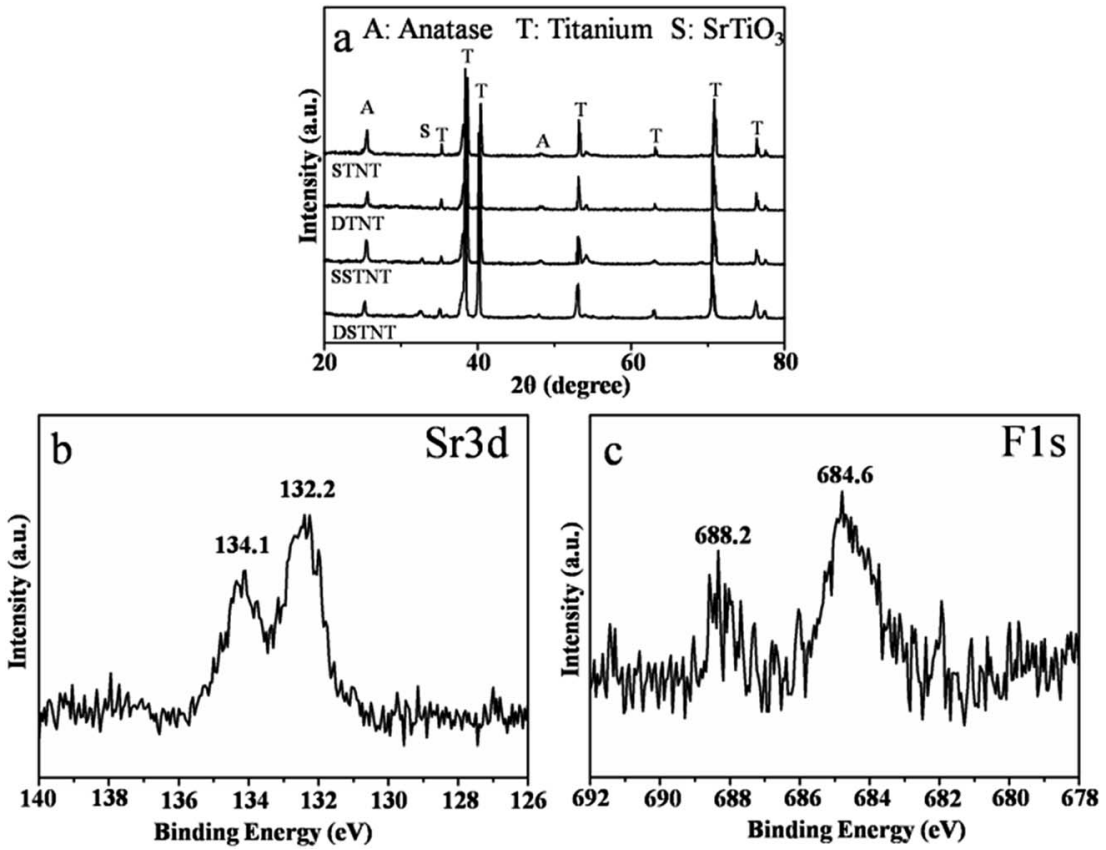

Fig. 4 (a) XRD patterns of annealed double and single layer walled $\mathrm{TiO}_{2}$ nanotube arrays with and without hydrothermal treatment; (b) and (c) high resolution XPS profiles of $\mathrm{Sr} 3 \mathrm{~d}$ and $\mathrm{F}$ 1s of annealed double layer walled $\mathrm{TiO}_{2}$ nanotube arrays with hydrothermal treatment.

patterns of double layer walled $\mathrm{TiO}_{2}$ nanotube arrays with hydrothermal treatment in solutions of four different strontium acetate concentrations $\left(0.02,0.04,0.06\right.$ and $\left.0.08 \mathrm{~mol} \mathrm{~L}^{-1}\right)$. Identical crystalline structure can be observed for all samples with characteristic peaks of titanium, anatase $\mathrm{TiO}_{2}$ and perovskite $\mathrm{SrTiO}_{3}$ in the XRD patterns. No other strontium containing phases were formed. XPS analysis was taken to further investigate the chemical composition of double layer walled $\mathrm{SrTiO}_{3} /$ $\mathrm{TiO}_{2}$ nanotube arrays. The fully scanned spectrum showed the existence of $\mathrm{Sr}, \mathrm{Ti}, \mathrm{O}, \mathrm{C}$ and $\mathrm{F}$ in the double layer walled $\mathrm{SrTiO}_{3} /$ $\mathrm{TiO}_{2}$ nanotube arrays, while the $\mathrm{C}$ element could be the adventitious carbon based contaminant (Fig. S3†). The high resolution XPS spectra with scanning over the area of Sr $3 \mathrm{~d}$ and F 1s were also measured and shown in Fig. $4 \mathrm{~b}$ and c. In Fig. $4 \mathrm{~b}$, the spectrum of $\mathrm{Sr} 3 \mathrm{~d}$ contains two peaks of $\mathrm{Sr} 3 \mathrm{~d}_{5 / 2}$ and $\mathrm{Sr} 3 \mathrm{~d}_{3 / 2}$ located at $132.2 \mathrm{eV}$ and $134.1 \mathrm{eV}$ respectively. The former peak can be assigned to perovskite $\mathrm{SrTiO}_{3}$ material, and the latter peak can be ascribed to SrO complexes. ${ }^{37,38}$ In Fig. 4c of XPS spectrum of F 1s, two contributions at $684.6 \mathrm{eV}$ and $688.2 \mathrm{eV}$ can be observed clearly. The peak at $684.6 \mathrm{eV}$ is in good agreement with those reported for $\mathrm{F}^{-}$physically absorbed on the sample surface..$^{39}$ The second peak at $688.2 \mathrm{eV}$ corresponds to the doped fluoride in substitutional positions (e.g. $\mathrm{TiO}_{2-x} \mathrm{~F}_{x}$, $\left.\mathrm{SrTiO}_{3-x} \mathrm{~F}_{x}\right) .^{40,41}$ This is comparable different from the XPS spectrum of $\mathrm{F} 1 \mathrm{~s}$ for as anodized double layer walled $\mathrm{TiO}_{2}$ nanotube arrays (Fig. S1 $\dagger$ ). After anodization, only the peak located at $684.6 \mathrm{eV}$, which corresponds to physically absorbed fluoride, can be observed. This indicates that fluoride were doped into crystal lattice after hydrothermal and post-annealing treatment. Since the ions radius of fluoride $(0.133 \mathrm{~nm})$ is virtually identical to that of oxygen $(0.132 \mathrm{~nm})$, fluoride may occupy the oxygen sites in the lattice, and the fluoride doped
$\mathrm{SrTiO}_{3} / \mathrm{TiO}_{2}$ nanotube arrays were formed. In one word, the XRD and XPS results concluded that $\mathrm{SrTiO}_{3} / \mathrm{TiO}_{2}$ nanotube arrays have been formed through hydrothermal treatment, and fluoride ions were also doped inside.

The photoelectric conversion performances of the four samples (STNT, DTNT, SSTNT and DSTNT) have been examined by measuring the photocurrent responses under chopped simulated solar light irradiation at a bias potential of $0.3 \mathrm{~V}$. Fig. 5a represents the comparable results. For all the four samples, no significant photocurrent can be observed as soon as the irradiation of light turned off. When the light was turned on, the photocurrent densities for STNT, DTNT, SSTNT, DSTNT reached $12.5,15.5,30.5$, and $40.5 \mu \mathrm{A} \mathrm{cm}^{-2}$ respectively, and the on-off cycles were reproducible. By comparison, the photocurrent density of double and single layer walled $\mathrm{TiO}_{2}$ nanotube arrays raised with the coupling of $\mathrm{SrTiO}_{3}$. In fact, the photocurrent appeared due to generation and separation of electronhole pairs at the nanotube arrays/electrolyte interface. ${ }^{42}$ Firstly, under simulated solar light irradiation, $\mathrm{TiO}_{2}$ and $\mathrm{SrTiO}_{3}$ can both be excited to produce $\mathrm{e}^{-} / \mathrm{h}^{+}$pairs. Since the conductive band (CB) of $\mathrm{SrTiO}_{3}$ is situated above the $\mathrm{CB}$ of $\mathrm{TiO}_{2}$, electrons in the $\mathrm{CB}$ of $\mathrm{SrTiO}_{3}$ will migrate to the $\mathrm{CB}$ of $\mathrm{TiO}_{2}$, while holes in the valence band $(\mathrm{VB})$ of $\mathrm{TiO}_{2}$ will inversely migrate to the $\mathrm{VB}$ of $\mathrm{SrTiO}_{3}{ }^{21}{ }^{21}$ Thus, separation of photo-generated $\mathrm{e}^{-} / \mathrm{h}^{+}$pairs could be efficiently promoted through coupling of $\mathrm{SrTiO}_{3}$, and photocurrent density for $\mathrm{SrTiO}_{3} / \mathrm{TiO}_{2}$ nanotube arrays increased compared to that for $\mathrm{TiO}_{2}$ nanotube arrays. Second, red shift of absorption edge has been observed for both double and single layer walled $\mathrm{SrTiO}_{3} / \mathrm{TiO}_{2}$ nanotube arrays (Fig. 5b). Different from double and single layer walled $\mathrm{TiO}_{2}$ nanotube arrays, there are clear response in the visible region for double and single layer walled $\mathrm{SrTiO}_{3} / \mathrm{TiO}_{2}$ nanotube arrays. The optical responses 

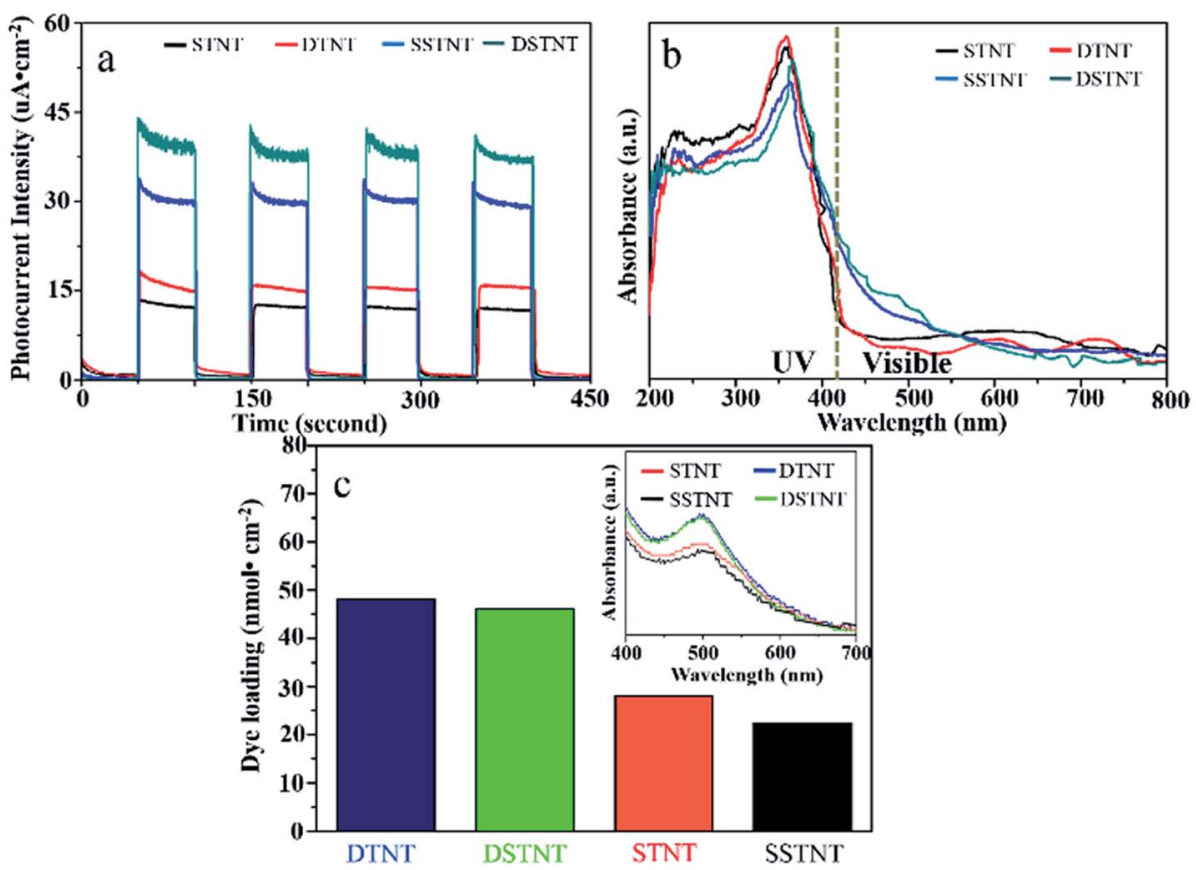

Fig. 5 (a) $j-t$ curves upon chopped simulated solar light illumination at $0.3 \mathrm{~V}$ vs. Ag/AgCl reference electrode, (b) UV-visible absorption spectra and (c) dye loading measurements of annealed double and single walled $\mathrm{TiO}_{2}$ nanotube arrays with and without hydrothermal treatment.

in the visible light region could be the doping of fluoride inside nanotube arrays. It has been reported that doping of fluoride may give rise to the modification of electronic structure around the $\mathrm{CB}$ edge of $\mathrm{TiO}_{2}$ and $\mathrm{SrTiO}_{3}{ }^{43,44}$ Moreover, according to ref. 44 and 45, doping of fluoride inside $\mathrm{SrTiO}_{3}$ might induce the formation of $\mathrm{Ti}^{3+}$ ions, which can lead to high visible light absorption capability. Therefore, both samples of SSTNT and DSTNT demonstrated significant visible light sensitiveness (Fig. 5b). This visible light sensitiveness can also improve the photocurrent densities under simulated solar light irradiation for $\mathrm{SrTiO}_{3} / \mathrm{TiO}_{2}$ nanotube arrays (Fig. 4a). Further observation from Fig. 4a also indicates that photocurrent densities of nanotube arrays with double layer walled structure is higher than that of nanotube arrays with single layer walled structure. The enhanced surface area may be responsible for the prompted photocurrent densities. The tube wall of double layer walled nanotube contains two layers, and the inner wall is loose and porous. The porosity of tube wall can contribute to the enlarged surface area of nanotube arrays. This is also confirmed in Fig. 5c. The dye loading of DTNT and DSTNT are 49 and $47 \mathrm{nmol}$ $\mathrm{cm}^{-2}$ respectively, which is higher than that of STNT and SSTNT (27 and $23 \mathrm{nmol} \mathrm{cm}{ }^{-2}$ ). In Fig. S4, $\dagger$ BET adsorption-desorption isotherms also demonstrated the higher specific surface area of double layer walled $\mathrm{SrTiO}_{3} / \mathrm{TiO}_{2}$ nanotubes compared to single layer walled $\mathrm{SrTiO}_{3} / \mathrm{TiO}_{2}$ nanotubes $\left(37.77 \mathrm{~m}^{2} \mathrm{~g}^{-1}>32.74 \mathrm{~m}^{2}\right.$ $\left.\mathrm{g}^{-1}\right)$. Due to the enlarged surface area, more active sites might be generated, and the photocurrent density will thus increased. ${ }^{46,47}$

As is well-known, photocatalytic properties of $\mathrm{TiO}_{2}$ is strongly related to the factors such as separation efficiency of $\mathrm{e}^{-} / \mathrm{h}^{+}$pairs, specific surface area and efficiency of visible light utilization etc. ${ }^{48}$ Based on the above discussions on Fig. 5, improved photocatalytic properties of nanotube arrays can be expected, examination on the photocatalytic properties of nanotube arrays has been conducted. With regarding to the photocatalytic test, the maximum absorption peaks of MB at $664 \mathrm{~nm}$ were measured for evaluating the apparent rate constant of different samples following a first order kinetics (see details in Fig. S6 $\dagger$ ). Fig. 6a-c show the pseudo-first-order kinetic rate plots for the four samples under different light sources, the corresponding rate constants were determined by the slope of the decay fits and are given in Fig. $6 \mathrm{~d}$. Without the samples, degradation rates of MB are all minimum, indicating. effective photocatalytic activity of nanotube arrays. Herein, photofading of MB is comparably faster under simulated solar light irradiation than that under UV light irradiation. The reason could be the higher light intensity of simulated solar light than that of UV light $\left(25.8 \mathrm{~mW} \mathrm{~cm}{ }^{2}>1.1 \mathrm{~mW} \mathrm{~cm}^{2}\right) .{ }^{49}$ Since $\mathrm{pH}$ value of MB solution is 9.1, nonelectronic reduction of $\mathrm{MB}^{+}$ by hydroxyl ions will occur and produce hydroxyl radicals under basic condition. ${ }^{50}$ The higher light intensity can promote the generation of hydroxyl radicals, which are strong oxidizing species. ${ }^{51,52}$ Therefore, photofading of methylene blue solution was faster under simulated solar light irradiation than that under UV light irradiation. With the existence of samples, rate constants for MB degradation over sample of DSTNT were calculated to be $0.13 \mathrm{~h}^{-1}, 0.15 \mathrm{~h}^{-1}$ and $0.53 \mathrm{~h}^{-1}$ under UV, visible and simulated solar light irradiation respectively, which are the highest among the four samples. This can be attributed to the synergetic effects of suppressed recombination of $\mathrm{e}^{-} / \mathrm{h}^{+}$ pairs, improved surface area and visible light sensitization (Fig. 5). Due to the synergetic effects, more electrons and holes will form, migrate to the surface of DSTNT, and generate increased number of hydroxyl radicals $\left({ }^{\circ} \mathrm{OH}\right)^{48,53,54}$ 

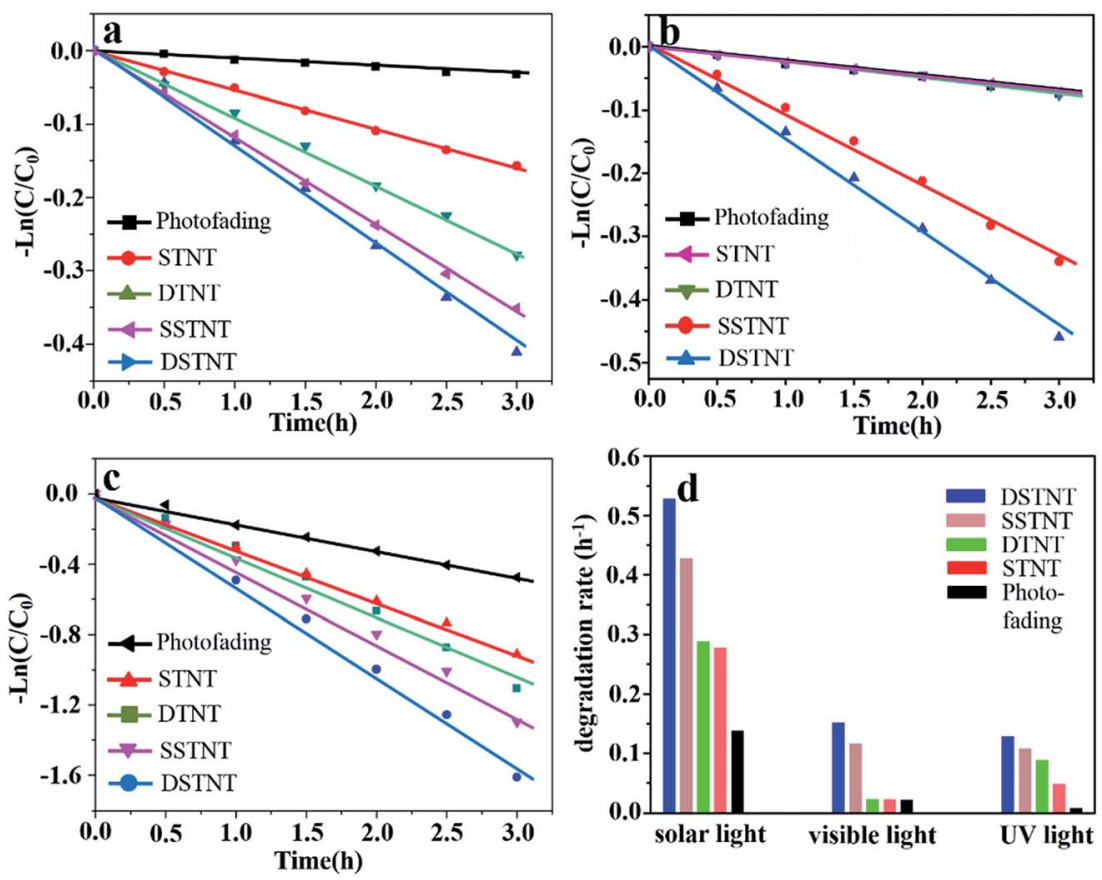

Fig. 6 Pseudo-first-order kinetic rate plots of the photocatalytic degradation of MB solution for various samples under (a) UV light, (b) visible light and (c) solar light irradiation; (d) degradation rates of MB solution for the four samples under different light irradiation.

$$
\begin{gathered}
\left(\mathrm{SrTiO}_{3} / \mathrm{TiO}_{2}\right)+h v \rightarrow\left(\mathrm{SrTiO}_{3}+\mathrm{TiO}_{2}\right)\left(\mathrm{e}_{\mathrm{CB}}{ }^{-}+\mathrm{h}_{\mathrm{VB}}{ }^{+}\right) \\
\mathrm{h}^{+}+\mathrm{OH}^{-} \rightarrow \cdot \mathrm{OH} \\
\mathrm{e}^{-}+\mathrm{O}_{2} \rightarrow \mathrm{O}_{2}^{\cdot-} \\
\mathrm{O}_{2}^{\cdot-}+\mathrm{H}_{2} \mathrm{O} \rightarrow \mathrm{HO}_{2}^{\cdot}+\mathrm{OH}^{-} \\
\mathrm{HO}_{2}^{\cdot}+\mathrm{H}_{2} \mathrm{O} \rightarrow \mathrm{H}_{2} \mathrm{O}_{2}+{ }^{\cdot} \mathrm{OH} \\
\mathrm{H}_{2} \mathrm{O}_{2} \rightarrow 2 \mathrm{OH}^{\cdot}
\end{gathered}
$$

$$
\mathrm{MB}+{ }^{\cdot} \mathrm{OH} \rightarrow \text { degradation products }
$$

The hydroxyl radicals, which are strong oxidizing agent, can decompose the MB to the final products. Finally, MB was most effectively degraded by the sample of DSTNT. While for other three samples (SSTNT, STNT and DTNT), the synergetic effect of improved specific surface area, visible light absorption and separation of electron-hole pairs cannot be realized, thus their photocatalytic activities decreased. For samples of STNT and DTNT, doping of fluoride inside nanotube arrays did not occur, both single and double layer walled $\mathrm{TiO}_{2}$ nanotube arrays are visible light insensitive (Fig. 5b), and demonstrated no photocatalytic activity under visible light irradiation. As shown in Fig. $6 \mathrm{~b}$ and d, degradation rates of MB over samples of STNT and DTNT are the same as that without samples. For single layer walled structure, the specific surface area is lower than that of double layer walled structure. So samples of both STNT and SSTNT demonstrated lower photocatalytic activities than samples of SSTNT and DSTNT. It can also be noted that degradation rates of $\mathrm{MB}$ solution for all samples are higher under simulated solar light irradiation than that under ultraviolet light irradiation. With regarding to this result, one reason could be the higher intensity of simulated solar light. Since the photocatalytic efficiency of nanotube array is light intensity dependent, under higher intensity, a larger amount of hydroxyl radicals can be generated. Another reason could be the accelerated photolysis rate of MB solution under simulated solar light irradiation. As discussed above, nonelectronic reduction of $\mathrm{MB}^{+}$by hydroxyl ions will be accelerated under higher light intensity. This may also generate more hydroxyl radicals. Therefore, MB solution was degraded faster under simulated solar light irradiation for all samples.

In addition to photocatalytic property, the hydroxylapatite formation ability of the as prepared samples was also tested. Fig. 7 shows the XRD patterns of the four samples (STNT, DTNT, SSTNT and DSTNT) after soaking in SBF for 18 days. The peaks with $2 \theta$ of $32.2^{\circ}$, which belong to hydroxylapatite, were detected for all the samples, indicating the successful formation of hydroxylapatite on the surface. Particularly, it is noteworthy that the intensity of hydroxylapatite peaks for the four samples are different. This can be ascribed to the different hydroxylapatite formation ability of the four samples. We further conducted SEM observation to examine the surface morphologies with hydroxylapatite formation, and the results are shown in Fig. 8. For the double and single layer walled $\mathrm{TiO}_{2}$ nanotube arrays, just some hydroxylapatite particles were observed on the surface (Fig. 8a and c), the porous structure of nanotube mouths can still be recognized clearly. Differently, the surface of another two samples (DSTNT and SSTNT) were fully covered by thick hydroxylapatite layer (Fig. 8b and d). To be more detailed, Fig. $8 \mathrm{~b}$ shows many cracks of hydroxylapatite film, while the 


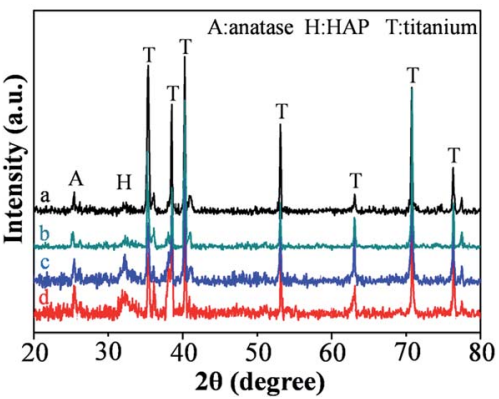

Fig. 7 XRD patterns of annealed double and single layer walled $\mathrm{TiO}_{2}$ nanotube arrays with and without hydrothermal treatment after soaking in SBF for 18 days. (a) STNT, (b) DTNT, (c) SSTNT and (d) DSTNT.

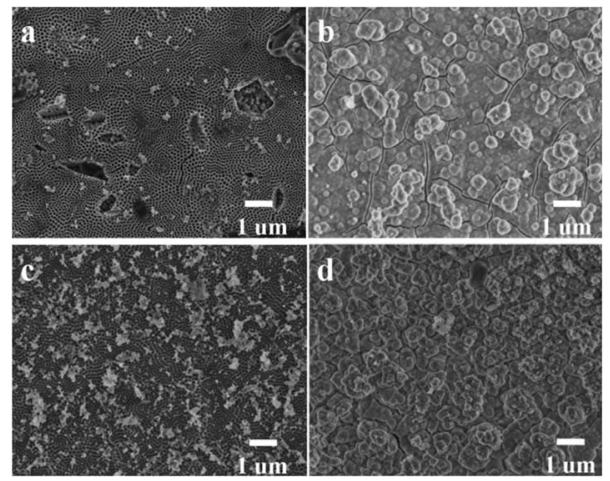

Fig. 8 SEM images for the samples of (a) STNT, (b) SSTNT, (c) DTNT and (d) DSTNT after soaking in SBF for 18 days.

cracks disappeared in Fig. 8d. In other words, the hydroxylapatite layer could be denser for DSTNT than that for SSTNT. From above comparison, it can be concluded that, as the photocatalytic activity, the double layer walled $\mathrm{SrTiO}_{3} / \mathrm{TiO}_{2}$ nanotube arrays also showed the highest hydroxylapatite formation ability among the four samples. In fact, according to ref. 55 and 56, subtle dissolution of $\mathrm{SrTiO}_{3}$ can occur during SBF immersion test as follows:

$$
\mathrm{SrTiO}_{3}+\mathrm{H}_{2} \mathrm{O} \rightarrow \mathrm{Sr}^{2+}+\mathrm{TiO}_{2}+2 \mathrm{OH}^{-}
$$

This indicates that $\mathrm{SrTiO}_{3}$ can behave as insoluble $\mathrm{TiO}_{2}$ and partially soluble SrO in the aqueous solution. Therefore, for the formation hydroxylapatite layer, $\mathrm{Ca}^{2+}$ is firstly adsorbed around sample surface of negative charges for the isoelectric point of $\mathrm{TiO}_{2}$ at $\mathrm{pH}=6.2$, and then $\mathrm{HPO}_{4}{ }^{2-}$ groups are caught by the hydroxyl groups such as $\mathrm{Ti}-\mathrm{OH}$ which work as inducers for hydroxylapatite formation. Herein, for the double layer walled $\mathrm{SrTiO}_{3} / \mathrm{TiO}_{2}$ nanotube arrays, the $\mathrm{OH}^{-}$concentration at the vicinity of sample surface will increase due to the dissolution of $\mathrm{SrTiO}_{3} \cdot{ }^{57}$ It has also been reported that fluoride doping can generate more hydroxyl groups for the charge imbalance between $-1 \mathrm{~F}$ ions and -2 oxygen sites. ${ }^{40}$ Fluoride also has higher affinity in respect to oxygen. The existing hydrogen atoms of the $\mathrm{OH}^{-}$group in hydroxyapatite will be tightly bonded to the nearby $\mathrm{F}^{-}$anions. ${ }^{58}$ This can improve the chemical stability of hydroxylapatite. The above factors can promote the formation of hydroxylapatite. Moreover, for the porosity of tube wall, double layer walled $\mathrm{SrTiO}_{3} / \mathrm{TiO}_{2}$ nanotube arrays has rougher surface, this may also contribute to a larger number of reactive initiation sites and promote the hydroxylapatite formation. ${ }^{59}$ It has also been reported that the piezoelectricity of $\mathrm{SrTiO}_{3}$ can also facilitate the formation of hydroxyapatite. ${ }^{60}$ The stress inside nanotube array could induce negative polarization of compounds surface. ${ }^{61,62}$ Thus, adsorption of charge compensatory $\mathrm{Ca}^{2+}$ ions will be accelerated, and the hydroxylapatite formation ability is improved.$^{63}$ Considering above discussions, the hydroxylapatite formation ability is highest for double layer walled $\mathrm{SrTiO}_{3} / \mathrm{TiO}_{2}$ nanotube arrays, while other three samples are inefficient for hydroxylapatite formation.

\section{Conclusion}

In summary, through hydrothermal treatment in strontium acetate containing solution, we have successfully prepared fluoride doped $\mathrm{SrTiO}_{3} / \mathrm{TiO}_{2}$ nanotube arrays with both double and single layer walled structure. It was found that the preferred accumulation of strontium occurred in the outer layer of tube wall for double layer walled $\mathrm{TiO}_{2}$ nanotube. Due to the fluoride doped inside, both double and single layer walled $\mathrm{SrTiO}_{3} / \mathrm{TiO}_{2}$ nanotube arrays demonstrated absorption of visible light. For the formation of hetero-junction between $\mathrm{TiO}_{2}$ and perovskitetype $\mathrm{SrTiO}_{3}$, separation of photogenerated $\mathrm{e}^{-} / \mathrm{h}^{+}$pairs has been efficiently improved. In addition, dye loading test indicated a higher specific surface area of double layer walled nanotube arrays than that of single layer walled nanotube arrays. Owning to the synergetic effect of above three factors, fluoride doped double layer walled $\mathrm{SrTiO}_{3} / \mathrm{TiO}_{2}$ nanotube arrays exhibited the highest photocatalytic activities. The degradation rates of methylene blue over fluoride doped double layer walled $\mathrm{SrTiO}_{3} / \mathrm{TiO}_{2}$ nanotube arrays are $0.13 \mathrm{~h}^{-1}, 0.26 \mathrm{~h}^{-1}$ and $0.53 \mathrm{~h}^{-1}$ respectively under ultraviolet, visible and simulated solar light irradiation. Formation of $\mathrm{SrTiO}_{3}$, fluoride doping and double layer walled structure can also stimulate the growth of hydroxylapatite on the surface of nanotube arrays by producing a larger number of hydroxyl ions, hydroxyl groups and initiation sites. Thus the fluoride doped double layer walled $\mathrm{SrTiO}_{3} / \mathrm{TiO}_{2}$ nanotube arrays also showed highest hydroxylapatite formation ability for the biomedical applications. The general concept reported in this article can be extended to the fabrication of other perovskite-type titanate nanotube arrays for applications such as photocatalysis, biomedicine and nanoscale electronics.

\section{Conflicts of interest}

There are no conflicts to declare.

\section{Acknowledgements}

This work was supported by the National Natural Science Foundation of China (Grant No. 51602292), Shanxi Province 
Science Foundation for Youths (Grant No. 201701D221087) and the starting fund for scientific research of North University of China (Grant No. 130082).

\section{References}

1 V. Zwilling, E. Darque-Ceretti and A. Boutry-Forveille, Electrochim. Acta, 1999, 45, 921-929.

2 J. Xing, H. Li, Z. Xia, J. Chen, Y. Zhang and L. Zhong, Ind. Eng. Chem. Res., 2014, 53, 10667-10672.

3 N. K. Shrestha, J. M. Macak, F. Schmidt-Stein, R. Hahn, C. T. Mierke, B. Fabry and P. Schmuki, Angew. Chem., 2008, 120, 1-5.

4 W. Guo, X. Xue, S. Wang, C. Lin and Z. L. Wang, Nano Lett., 2012, 12, 2520-2523.

5 S. Berger, A. Ghicov, Y. C. Nah and P. Schmuki, Langmuir, 2009, 25, 4841-4844.

6 J. M. Macak, M. Zlamal, J. Krysa and P. Schmuki, Small, 2007, 2, 300-304.

7 C. V. Wilmowsky, S. Bauer, R. Lutz, M. Meisel, F. W. Neukam, T. Toyoshima, P. Schmuki, E. Nkenke and K. A. Schlegel, J. Biomed. Mater. Res., Part B, 2009, 89, 165-171.

8 Y. Y. Song, F. Schmidt-Stein, S. Berger and P. Schmuki, Small, 2010, 6, 1180-1184.

9 K. Lee, A. Mazare and P. Schmuki, Chem. Rev., 2014, 114, 9385-9454.

10 I. Paramasivam, H. Jha, N. Liu and P. Schmuki, Small, 2012, 8(20), 3073-3103.

11 H. G. Yun, J. H. Park, B. S. Bae and M. G. Kang, J. Mater. Chem., 2011, 21, 3558-3561.

12 K. S. Raja, M. Misra and K. Paramguru, Mater. Lett., 2005, 59, 2137-2141.

13 X. Luan, D. Guan and Y. Wang, J. Phys. Chem. C, 2012, 116, 14257-14263.

14 X. Zhang, L. Wang, C. Liu, Y. Ding, S. Zhang, Y. Zeng, Y. Liu and S. Luo, J. Hazard. Mater., 2016, 313, 244-252.

15 L. Hu, C. C. Fong, X. Zhang, L. L. Chan, P. K. S. Lam, P. K. Chu, K. Y. Wong and M. Yang, Environ. Sci. Technol., 2016, 50, 4430-4438.

16 M. Z. Ge, C. Y. Cao, S. H. Li, Y. X. Tang, L. N. Wang, N. Qi, J. Y. Huang, K. Q. Zhang, S. S. Al-Deyab and Y. K. Lai, Nanoscale, 2016, 8, 5226-5234.

17 G. G. Bessegato, J. C. Cardoso and M. V. B. Zanoni, Catal. Today, 2015, 240, 100-106.

18 K. F. Huo, X. M. Zhang, H. R. Wang, L. Z. Zhao, X. Y. Liu and P. K. Chu, Biomaterials, 2013, 34, 3467-3478.

19 L. Z. Zhao, H. R. Wang, K. F. Huo, X. M. Zhang, W. Wang, Y. M. Zhang, Z. F. Wu and P. K. Chu, Biomaterials, 2013, 34, 19-29.

20 X. Zhang, B. Gao, L. Hu, L. Li, W. Jin, K. Huo and P. K. Chu, CrystEngComm, 2014, 16, 10280-10285.

21 J. Ng, S. Xu, X. Zhang, H. Y. Yang and D. D. Sun, Adv. Funct. Mater., 2010, 20, 4287-4294.

22 X. Zhang, K. Huo, L. Hu and P. K. Chu, J. Am. Chem. Soc., 2010, 93, 2771-2778.

23 H. M. Kim, H. Takadama, T. Kokubo, S. Nishiguchi and T. Nakamura, Biomaterials, 2000, 21, 353-358.
24 Y. Zhang, Y. Han and L. Zhang, J. Mater. Sci. Technol., 2016, 32, 930-936.

25 Y. Wang, D. Zhang, C. Wen and Y. Li, ACS Appl. Mater. Interfaces, 2015, 16018-16026.

26 F. Riboni, N. T. Nguyen, S. So and P. Schmuki, Nanoscale Horiz., 2016, 1, 445-466.

27 C. Xue, T. Yonezawa, M. T. Nguyen and X. Lu, Langmuir, 2015, 31, 1575-1580.

28 Y. Liu, K. Mu, G. Yang, H. Peng, F. Shen, L. Wang, S. H. Deng, X. Zhang and Y. Zhang, New J. Chem., 2015, 39, 3923-3928.

29 K. F. Huo, H. R. Wang, X. M. Zhang, Y. Cao and P. K. Chu, ChemPlusChem, 2012, 77, 323-329.

30 C. Xue, T. Narushima, Y. Ishida, T. Tokunaga and T. Yonezawa, ACS Appl. Mater. Interfaces, 2014, 6, 19924-19932.

31 K. Okada, Electrochemical Oxidation of Glycerol in a ProtonExchange-Membrane Reactor, The University of Michigan, 2013.

32 C. Xue, S. Hu, W. Liu, Q. Chang, T. Yonezawa and J. Yang, Funct. Mater. Lett., 2017, 10, 1750019-1750023.

33 A. Valota, D. J. LeClere, P. Skeldon, M. Curioni, T. Hashimoto, S. Berger, J. Kunze, P. Schmuki and G. E. Thompson, Electrochim. Acta, 2009, 54, 4321-4327.

34 C. Xue, T. Narushima and T. Yonezawa, J. Inorg. Organomet. Polym. Mater., 2013, 23, 239-242.

35 Y. Xin, J. Jiang, K. Huo, T. Hu and P. K. Chu, ACS Nano, 2009, 3, 3228-3234.

36 S. Zhang, J. Liu, Y. Han, B. Chen and X. Li, Mater. Sci. Eng., B, 2004, 110, 11-17.

37 H. Bai, J. Juay, Z. Liu, X. Song, S. S. Lee and D. D. Sun, Appl. Catal., B, 2012, 125, 367-374.

38 W. D. Yang, J. Mater. Sci., 1999, 34, 3533-3544.

39 J. C. Yu, J. Yu, W. Ho, Z. Jiang and L. Zhang, Chem. Mater., 2002, 14, 3808-3816.

40 J. K. Zhou, L. Lv, J. Yu, H. L. Li, P. Z. Guo, H. Sun and X. S. Zhao, J. Phys. Chem. C, 2008, 112, 5316-5321.

41 J. Wang, S. Yin, Q. Zhang, F. Saito and T. Sato, Solid State Ionics, 2004, 172, 191-195.

42 J. G. Yu, G. P. Dai and B. B. Huang, J. Phys. Chem. C, 2009, 113, 16394.

43 T. Yamaki, T. Umebayashi, T. Sumita, S. Yamamoto, M. Maekawa, A. Kawasuso and H. Itoh, Nucl. Instrum. Methods Phys. Res., Sect. B, 2003, 206, 254-258.

44 H. W. Kang and S. B. Park, Chem. Eng. Sci., 2013, 100, 384391.

45 J. Wang, S. Yin, Q. Zhang, F. Saito and T. Sato, J. Mater. Sci., 2004, 39, 715-717.

46 S. Sofiane and M. Bilel, J. Photochem. Photobiol., A, 2016, 324, 126-133.

47 N. T. Nguyen, S. Ozkan, I. Hwang, A. Mazare and P. Schmuki, Nanoscale, 2016, 8, 16868-16873.

48 G. Žerjav, M. S. Arshad, P. Djinović, I. Junkar, J. Kovač, J. Zavašnik and A. Pintar, Nanoscale, 2017, 9, 4578-4592.

49 T. Soltani and M. H. Entezari, J. Mol. Catal. A: Chem., 2013, 377, 197-203.

50 M. Misran, D. Matheus, P. Valente and A. Hope, Aust. J. Chem., 1994, 47, 209-216. 
51 H. Gnaser, M. R. Savina, W. F. Calaway, C. E. Tripa, I. V. Vervovkin and M. J. Pellin, Int. J. Mass Spectrom., 2005, 245, 61-67.

52 R. Azmat and F. Uddin, Chin. J. Chem., 2009, 27, 1237-1243.

53 J. Zhang, Y. Wang, C. Yu, X. Shu, L. Jiang, J. Cui, Z. Chen, T. Xie and Y. Wu, New J. Chem., 2014, 38, 4975-4984.

54 T. Cao, Y. Li, C. Wang, C. Shao and Y. Liu, Langmuir, 2011, 27, 2946-2952.

55 P. Li, I. Kangasniemi, K. de Groot and T. Kokubo, J. Am. Ceram. Soc., 1994, 77, 1307-1312.

56 Y. Xin, J. Jiang, K. Huo, T. Hu and P. K. Chu, ACS Nano, 2009, 3, 3228-3234.
57 T. Miyazaki, H. M. Kim, T. Kokubo, C. Ohtsuki, H. Kato and T. Makamura, Biomaterials, 2002, 23, 827-832.

58 Y. Chen and X. Miao, Ceram. Int., 2004, 30, 1961-1965.

59 H. Tsuchiya, J. M. Macak, L. Muller, J. Kunze, F. Muller, P. Greil, S. Virtanen and P. Schmuki, J. Biomed. Mater. Res., Part A, 2010, 77, 534-541.

60 J. Zhai, Q. Wang, J. Zeng, J. Chen, X. Yi, Z. Shi, G. Tian, P. Yu and C. Ning, RSC Adv., 2017, 7, 32974-32981.

61 A. A. Marino and R. O. Becker, Nature, 1970, 228, 473-474. 62 H. M. Ouyang, G. T. Fei, Y. Zhang, H. Su, Z. Jin, S. H. Xu and L. D. Zhang, J. Mater. Chem. C, 2013, 1, 7498-7506.

63 S. Itoch, S. Nakamura, M. Nakamura, K. Shinomiya and K. Yamashita, Biomaterials, 2006, 27, 5572-5579. 